\title{
A review of jellyfish aggregations, focusing on India's coastal waters
}

\author{
Sanjiba Kumar Baliarsingh, Aneesh Anandrao Lotliker ${ }^{*}$, Suchismita Srichandan, Alakes Samanta, Nimit Kumar and \\ T. M. Balakrishnan Nair
}

\begin{abstract}
A review of jellyfish aggregations focused on India's coastal waters was conducted, with the aim to enhance understanding of conducive conditions and subsequent ecological impacts. Jellyfish swarming, as well as their beach strandings, have been reported from many areas of the world-including India's coastal waters. A variety of natural (winds, tidal fronts, surface currents, water temperature, salinity, turbidity, dissolved oxygen) and anthropogenic (water quality deterioration, overfishing, translocation, habitat modification) factors play pivotal roles in triggering jellyfish aggregations. Jellyfish aggregation events in the forms of their swarming in coastal waters and beach strandings have resulted in ephemeral nuisances such as water quality deterioration, food chain alterations, hindrance in seawater uptake by power plants, clogging of nets during fishing operations, and tourism declines. Several well-known Indian tourist beaches (e.g., Puri, Chennai, Goa, and Mumbai) have experienced beach strandings. Despite recurrence of such events, jellyfishes are relatively less scientifically investigated and monitored in Indian coastal waters. Therefore, it is important to determine the environmental conditions that trigger jellyfish swarming, in order to develop effective monitoring and prediction strategies. This study additionally proposes a conceptual framework towards development of a jellyfish monitoring system for Indian waters using satellite and model data.
\end{abstract}

Keywords: Jellyfish, Swarming, Coast, Water quality, Bay of Bengal, Arabian Sea

\section{Background}

Jellyfishes constitute an important group of marine animals, which are broadly distributed in many coastal and open ocean regions. These gelatinous animals occur as meroplankton (transient planktonic phases) and holoplankton (permanent pelagic residents) (Richardson et al. 2009; Sahu and Panigrahy 2013). Some jellyfish species form dense aggregations during favorable environmental conditions. Jellyfish growth and reproduction rates vary extensively with changes in environmental conditions, which lead to characteristic patchy distributions, dense aggregations, and subsequent population collapses (Purcell 2005). Jellyfish aggregations in coastal regions include swarming events and beach strandings

\footnotetext{
*Correspondence: aneesh@incois.gov.in

Indian National Centre for Ocean Information Services, Ministry of Earth Sciences, Govt. of India, Hyderabad 500090, India
}

that often result in water quality deterioration, trophic disturbance, and socio-economic losses (Richardson et al. 2009). In addition, jellyfish outbreaks exert significant impacts on tourism, recreational activities, and human health through toxic stinging from their nematocysts (Burnett 2001; Macrokanis et al. 2004). Episodes of jellyfish swarming have received substantial attention in recent times. However, the study of these organisms remains very subjective due to broad definitions and limited observational techniques (Brotz et al. 2012).

In peninsular Indian seas and coastal regions, jellyfish swarming and beach strandings have been reported sporadically (Fig. 1). Nuisances have included adverse impacts on tourism, fishing, and water intake by coastal power plants. On this backdrop, this review emphasizes (i) the environmental parameters conducive for jellyfish

\section{Springer Open}

(c) The Author(s). 2020 Open Access This article is licensed under a Creative Commons Attribution 4.0 International License, which permits use, sharing, adaptation, distribution and reproduction in any medium or format, as long as you give appropriate credit to the original author(s) and the source, provide a link to the Creative Commons licence, and indicate if changes were made. The images or other third party material in this article are included in the article's Creative Commons licence, unless indicated otherwise in a credit line to the material. If material is not included in the article's Creative Commons licence and your intended use is not permitted by statutory regulation or exceeds the permitted use, you will need to obtain permission directly from the copyright holder. To view a copy of this licence, visit http://creativecommons.org/licenses/by/4.0/. 


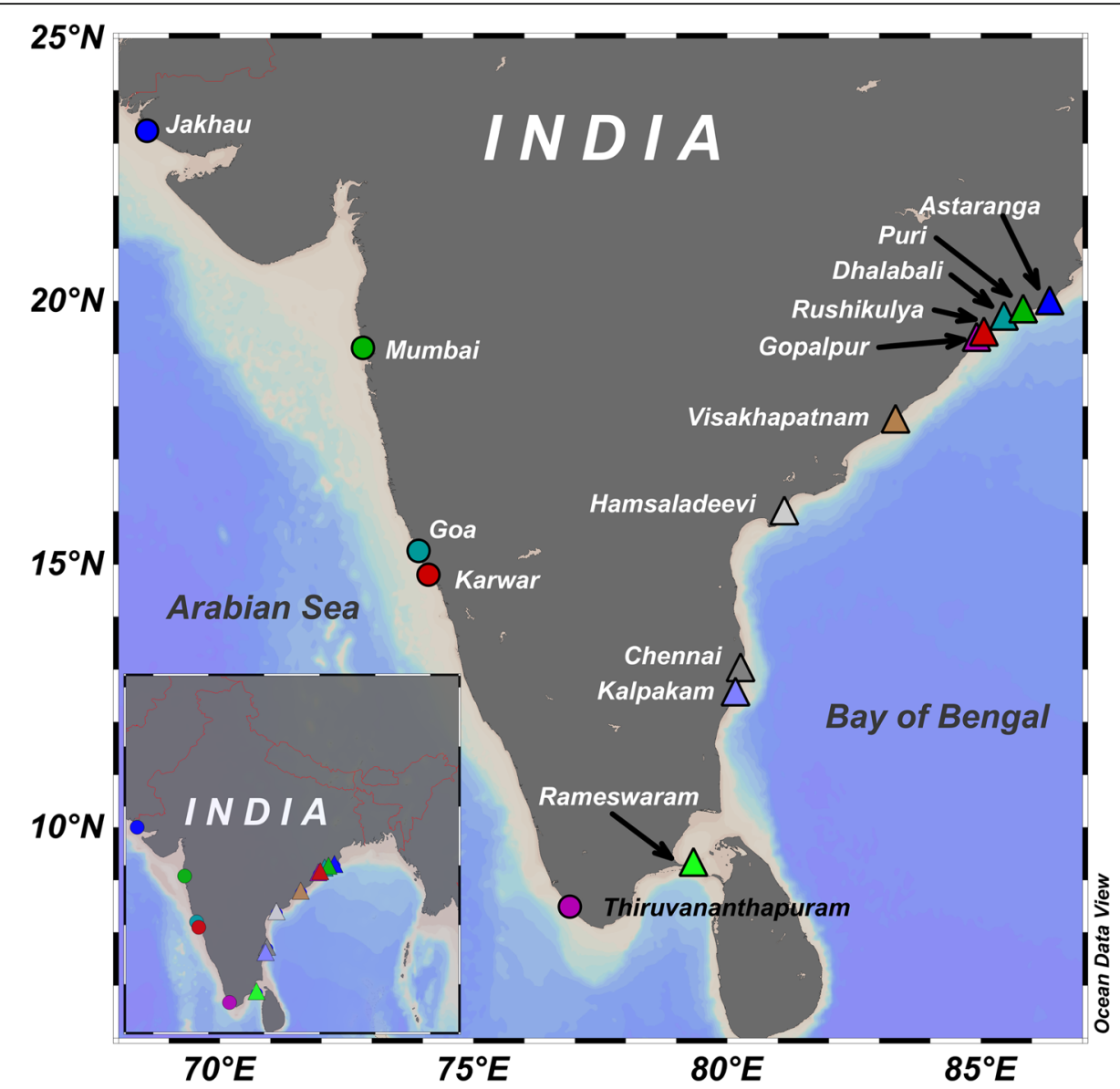

Fig. 1 Jellyfish swarming and beach stranding events reported along the Indian coast from 1995 to 2019. Details are provided in Table 1

swarming, (ii) impacts of swarming on the environment and socio-economy, (iii) documentation of swarming/ beach strandings in Indian coastal waters/beaches, and (iv) a conceptual framework for possible monitoring.

\section{Environmental variables for jellyfish swarming}

Jellyfishes can survive under adverse environmental conditions and can quickly multiply during favorable ones. Their swarming can be triggered by natural (winds, tidal fronts, surface currents, water temperature, salinity, turbidity, dissolved oxygen) and anthropogenic (water quality deterioration, overfishing, translocation, habitat modification) factors (Richardson et al. 2009). Local weather conditions, such as wind direction, play an essential role in accumulations of jellyfish assemblages in coastal waters. Onshore wind bursts also trigger localized jellyfish aggregations (Kaneda et al. 2007). Oceanic physical processes such as tidal fronts (Brodeur et al. 1997), convergent flow (Graham et al. 2001), and small linear surface convergences during Langmuir circulation also lead to jellyfish accumulations (Graham et al. 2001). Oceanic warming conditions often result in higher jellyfish densities. Rising temperatures in global seas may trigger the success of some jellyfish species and change species distributions (Xu et al. 2013; Sullivan et al. 2001). Jellyfishes match the ionic concentration of the surrounding seawater and tend to behaviorally remain in isohalines leading to localized accumulation (Graham et al. 2001). Freshwater pulses from river discharge lead to reductions of jellyfish aggregations (Amorim et al. 2018). Hence, obstructing the natural flow of rivers, by break walls, harbors, and other barriers, can influence the salinity of nearshore waters and possibly set up conducive conditions for jellyfish aggregations. Accidental introductions of invasive/alien jellyfishes can result in mass aggregations (Purcell et al. 2007). Jellyfish swarms often occur in surface waters, with surface currents providing advection (Johnson et al. 2005; Zavodnik 1987). Hence, jellyfish aggregations frequently occur at transport barriers due to alongshore currents (Franks 1992). Regional re-distribution or re-dispersion in density of a persistent jellyfish assemblage also may occur (Graham et al. 2001). In addition, deterioration of water quality, higher turbidity, and lower dissolved oxygen concentration can lead to patchy aggregation and swarms (Purcell et al. 2007). Aquaculture may inadvertently favor growth 
of jellyfish assemblages through several means, including dissolution of surplus fish food and artificial constructions-such as cages-can provide support for polyps and their subsequent strobilation (Purcell et al. 2007).

\section{Harmful consequences of jellyfish swarming}

Jellyfish swarms disturb marine ecosystems and can exert significant socio-economic effects. They predate on zooplankton, competing with fishes, leading to possible declines (Purcell 2003; Purcell et al. 2007). At higher density, jellyfish assemblages can interfere in aquatic nutrient cycling (Pitt et al. 2005). Further, jellyfish swarming during their decline phase contribute to the bottomward transport of organic carbon. Decomposed jellyfish material sinks quickly to the ocean floor and serves as food for benthic biota, in turn influencing benthic species' distributions (Billett et al. 2006; Sweetman and Chapman 2011). Dense jellyfish patches can choke fishing nets and hinder commercial catches (Graham et al. 2003).

When predominant, jellyfishes also may result in fish population declines by preying on fish eggs, larvae, and juveniles and may alter food webs (Lynam et al. 2005, 2006). For instance, the capture fishery declined significantly in the Black Sea subsequent to jellyfish invasion by Mnemiopsis leidyi, introduced through ship ballast water (Shiganova 1998). Jellyfish dominance also may affect coastal aquaculture causing toxic stinging, metabolic distress, and mass mortality of fishes (Purcell et al. 2013). As a consequence of stinging, fish growth may slow, resulting in economic loss for fishery and aquaculture industries (Baxter et al. 2011). Jellyfish can kill fish in aquaculture cages by irritating their gills, resulting in hemorrhage and asphyxiation (Purcell et al. 2007). Indirectly, jellyfish aggregations around mariculture cages interfere with water exchange, which may lead to hypoxia and fish suffocation (Doyle et al. 2008; Lucas et al. 2014).

Jellyfish may exert indirect deleterious impacts on coastal industries and tourism. Ingress of large quantities of jellyfish into seawater-based cooling systems of coastal power plants and desalination industries clog intake screens, resulting in temporary shutdowns (Masilamoni et al. 2000; Purcell et al. 2007). Such jellyfish outbreaks have hindered seawater intake by coastal power and desalination plants in China and Israel (Galil et al. 2009; Dong et al. 2010). Coastal tourism provides one of the major revenues of several sea-bordering countries. Shallow coastal water tourism resources include swimming, snorkeling, diving, and beach recreational activities. Jellyfish swarming in coastal waters and beach strandings sometimes impact tourism. For example, jellyfish proliferation along coastal stretches of Israel affected tourism, resulting in revenue loss (Ghermandi et al. 2015).
Jellyfish toxic stings can cause several human medical complications, including respiratory arrest, abdominal cramps, nausea, vomiting, headache, anxiety, and hypertension (Lucas et al. 2014). Jellyfish stinging, for example, has emerged as a human health hazard for beachgoers in southern Italy (De Donno et al. 2014).

\section{Jellyfish swarming in Indian coastal waters}

Jellyfish swarms as well as beach strandings have been reported from both the west (eastern Arabian Sea) and east (western Bay of Bengal) coasts of India (Fig. 1). Jellyfish aggregations and resultant environmental deterioration in Indian coastal waters are evident from several scientific publications, as well as local print and electronic media reports (Table 1). Despite that, jellyfish are relatively poorly investigated and monitored in Indian coastal waters (Sahu and Panigrahy 2013; Baliarsingh et al. 2015). Available reports (Table 1) suggest that a greater number of swarms and beach strandings have occurred on the east coast of India than on the west coast.

The Madras Atomic Power Station (MAPS) situated in the coastal southwestern Bay of Bengal at Kalpakkam faced short-term shut down due to ingress of large numbers of jellyfish in the plant cooling system (Masilamoni et al. 2000). In general, coastal areas often are preferred for power plant locations due to plentiful availability of seawater for condenser cooling. Temporary shutdown of MAPS due to jellyfish ingress during 1995-1996 resulted in high revenue loss ( 5.5 million Indian Rupees/day) (Masilamoni et al. 2000). In a subsequent study during 2013-2014 at the MAPS seawater intake screen, jellyfish contributed $~ 95 \%$ of the total biomass of impinged organisms (Kumar et al. 2017). Aggregations of large numbers of jellyfish in Kalpakkam coastal waters were closely linked to the coastal current pattern (Masilamoni et al. 2000). Significant increases in jellyfish abundance during the JulyAugust months could be due to the reproduction of scyphozoans and hydrozoans in warmer waters (water temperatures $\sim 26-28{ }^{\circ} \mathrm{C}$ ). The jellyfish species, Crambionella stuhlmanni, was observed to have higher abundance during the northeast monsoon period, attributed to low salinity that enhanced its rapid growth (Kumar et al. 2017).

Beach jellyfish strandings have been recurring in many pockets along the Indian coast. The tourist beaches along the east coast of India (e.g., Astaranga, Puri, Chilika Inlet region, and Gopalpur) are experiencing such occurrences that adversely impact tourism (Sahu and Panigrahy 2013; Sahu et al. 2020). In particular, massive outbreaks of blue button jellies (Porpita porpita) in coastal waters of the northwestern Bay of Bengal have resulted in massive beach strandings (Sahu et al. 2020) (Fig. 2). Bad odor from large numbers of dead jellies also impacted the tourist beaches of Gopalpur, particularly during 2012 (Sahu and Panigrahy 2013). The nearshore 


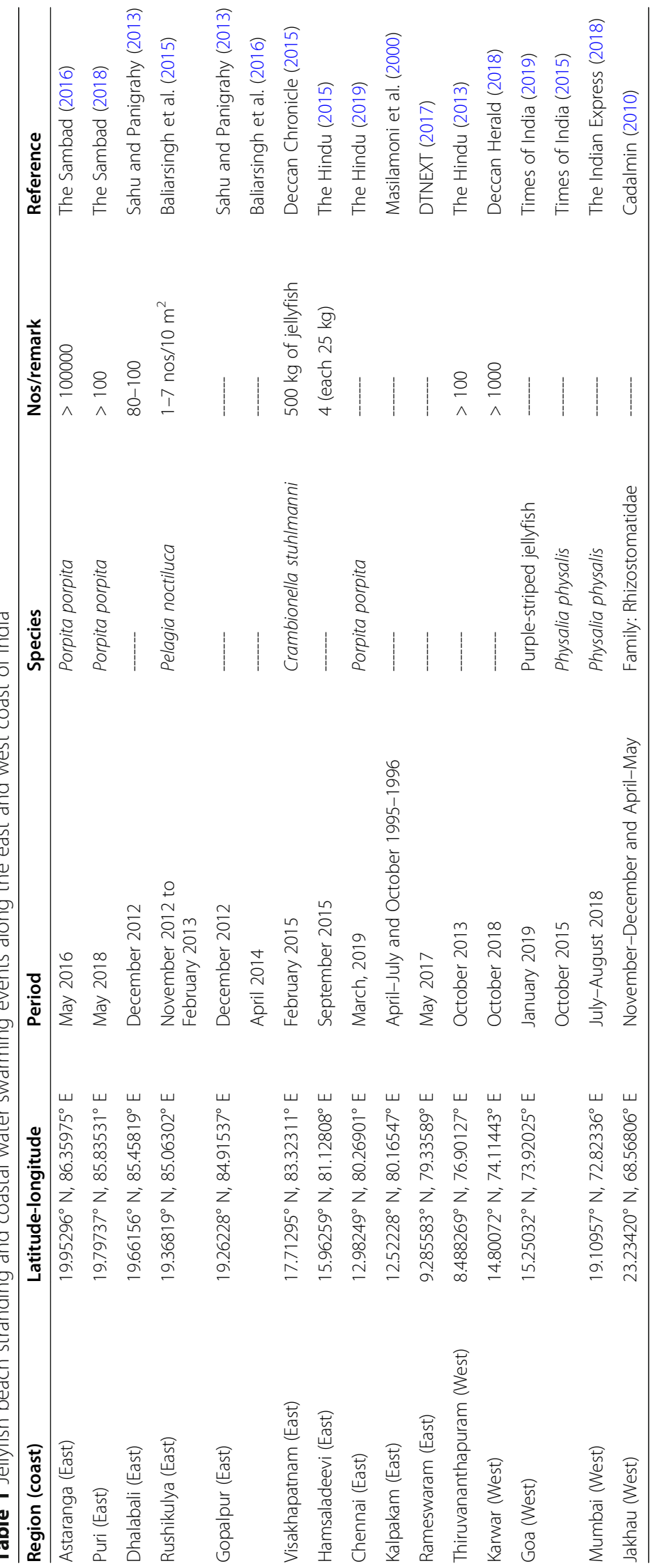



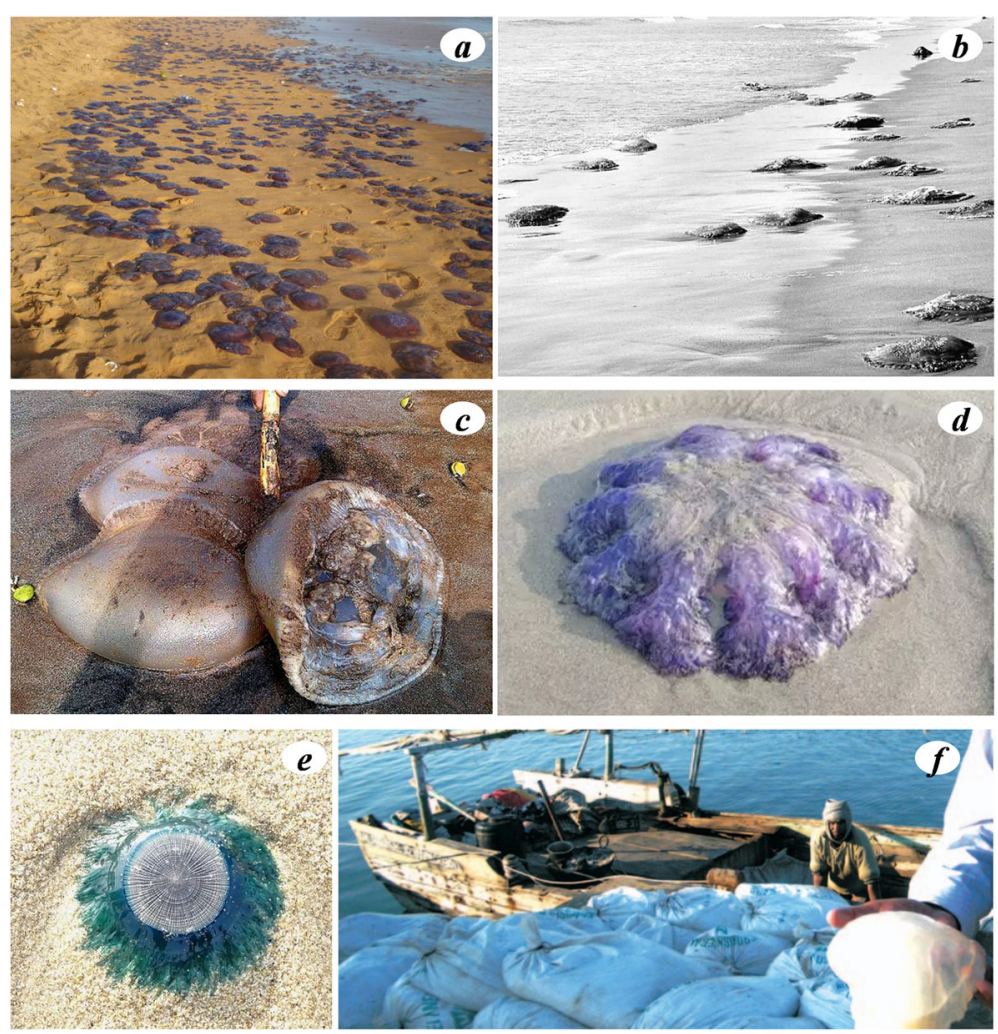

Fig. 2 Jellyfish beach stranding events along Indian coastal stretch reported at a Thiruvananthapuram, Source: The Hindu (2013); b Puri, Source: The Hindu (2016); c Hamsaladeevi, Source: The Hindu (2015); d Goa, Source: Times of India (2019); e Chennai, Source: The Hindu (2019); and f jellyfish fishery in coastal waters of Jakhau, Source: Cadalmin (2010)

waters of Mumbai also are experiencing jellyfish beach strandings. In particular, jellyfish stinging events have been reported during ceremonies that immerse religious idols in the sea. The impacts of overfishing and pollution are believed to contribute to jellyfish abundances (The Economic Times 2014).

Jellyfish aggregations also have been observed to hinder fishing operations in Indian coastal waters. Clogging of fishing nets was observed in estuaries and coastal waters of Kerala due to jellyfish swarms (The Economic Times 2014; The Statesman 2018). Seasonal (November-December and April-May) jellyfish infestation in coastal waters of Jakhau clog gillnets that mainly are operated by motorized boats (Cadalmin 2010). However, fishermen have taken an adaptive option to harvest jellyfishes due to heavy demand from China and South East Asian markets (Fig. 2f), reaching up to $\sim 800$ tonnes in a season (Cadalmin 2010). Similarly, an edible jellyfish (Crambionella annandalei) is harvested from Andhra Pradesh, on the Indian east coast during the pre-southwest monsoon period (Behera et al. 2020).

The prevalence of large numbers of jellyfishes in coastal waters of the northwestern Bay of Bengal also has influenced plankton ecology. Jellyfishes provide a competitive advantage to the heterotrophic dinoflagellate
Noctiluca scintillans by preying upon its food grazers, which cause red tides that have resulted in water quality deterioration in coastal Gopalpur, along the east coast of India (Baliarsingh et al. 2016). On the other hand, jellyfish prevalence in coastal northwestern Bay of Bengal, particularly off Gopalpur, serves as food for migratory sea turtles (Sahu and Panigrahy 2013). In general, although jellyfishes often are considered as "dead-ends" in marine trophic webs, they supply food for several other top-level consumers including commercially valuable fishes, sea turtles, and even humans (Purcell et al. 2007).

\section{Vulnerability of jellyfish aggregations in Indian coastal regions}

India has a vast coastline of $\sim 7500 \mathrm{~km}$ encompassing the west coast, east coast, and islands. The coastline's geographic structure varies among different pockets that can entrap wind-/current-driven jellyfish assemblages. Moreover, increasing pollutant loads in these coastal waters can deteriorate water quality, favoring jellyfish growth/proliferation. Coastal aquaculture is a fastest growing industry in India. According to a recent (20172018) report, a total of 152,595 ha area in nine Indian maritime states are under shrimp culture producing 680 , 
018 metric tonnes (MPEDA 2020). Rapidly increasing aquaculture/mariculture/cage culture practices also can act as a catalyst for jellyfish swarming by providing substrate for their benthic stages.

\section{Conceptual framework for a jellyfish monitoring advisory}

Jellyfish aggregations have been monitored through field observations, acoustics, Lagrangian particle tracking, video profiling, aerial survey, now-cast model currents, and unmanned aerial vehicles in various regions of the World Ocean (Graham et al. 2003; Johnson et al. 2005; Houghton et al. 2006; Nickell et al. 2010; Berline et al. 2013; Kim et al. 2015). However, in Indian waters, such methods have not been adopted yet. The conducive environmental conditions of ecological regions can be monitored with autonomous acoustic observations (Colombo et al. 2008; Han and Uye 2009). The major advantage of this approach is that continuous real-time monitoring could be beneficial for power plant operations. Along with acoustics, in situ observations of jellyfish and physico-chemical parameters need to be collected to understand what triggers outbreaks. Subsequent monitoring can be done using earth observation data from satellite and oceanographic models. Presently, AQUAX is providing jellyfish monitoring service in the Mediterranean Sea using satellite, in situ, and model datasets (www.aquaexploration.com/jellyx/). In this context, a conceptual framework is hereby proposed to develop a jellyfish monitoring system for Indian waters (Fig. 3).

The proposed detection and monitoring approach is based on environmental data from autonomous in situ instruments, satellites, and models. Wind velocity, ocean currents, sea surface temperature, chlorophyll, phytoplankton groups, and algal bloom scenarios can be retrieved efficiently from ocean observing remote sensing techniques (Table 2). Other components of the conceptual framework such as salinity, dissolved oxygen, nutrient, and river discharge can be recorded through automated buoy-based observatories and fine resolution models (Table 2). Qualitative and quantitative information on fisheries for vulnerable regions of jellyfish swarming can be obtained from respective authorities and the fishermen community (Table 2). Any radical or specific changes in their ecological habitats also can be monitored by regional environmental management agencies (Table 2). In specific to generate forecasts or advisories, bio-physical ocean model simulations can provide significant inputs for the proposed framework and account for limitations of satellite data. Notably, satellite data are unavailable under overcast conditions and have limitations in providing water column characteristics (Chakraborty et al. 2017). In this context, biogeochemical models coupled with ocean general circulation models can offer a solution to these data limitations. A

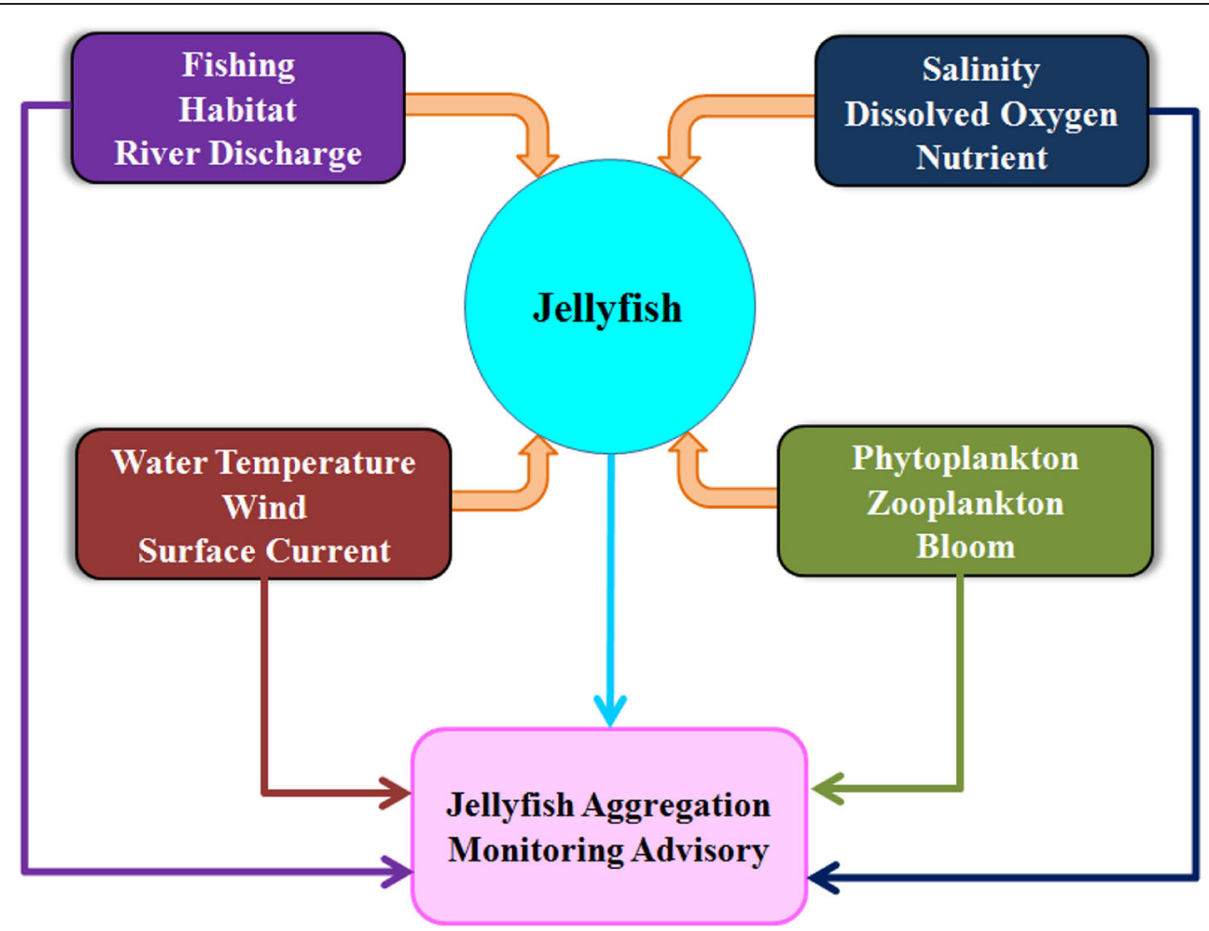

Fig. 3 Conceptual framework towards development of jellyfish aggregation monitoring advisory. Potential data source of environmental parameters is provided in Table 2 
Table 2 Potential data source of environmental parameters for generation of jellyfish aggregation monitoring advisory using the conceptual framework

\begin{tabular}{|c|c|}
\hline Parameters & Potential data source \\
\hline Sea surface current & $\begin{array}{l}\text { Satellite, Coastal Radar, Ocean } \\
\text { General Circulation Model }\end{array}$ \\
\hline Wind & $\begin{array}{l}\text { Satellite, Automatic Weather Station, } \\
\text { Ocean General Circulation Model }\end{array}$ \\
\hline Water temperature & $\begin{array}{l}\text { Satellite, Argo, Autonomous Data Buoy, } \\
\text { Ocean General Circulation Model }\end{array}$ \\
\hline Salinity & Argo, Autonomous Data Buoy \\
\hline Dissolved oxygen & $\begin{array}{l}\text { Argo, Autonomous Data Buoy, } \\
\text { physical-biogeochemical model }\end{array}$ \\
\hline Nutrient & $\begin{array}{l}\text { Argo, Autonomous Data Buoy, } \\
\text { physical-biogeochemical model }\end{array}$ \\
\hline Phytoplankton & $\begin{array}{l}\text { Satellite, Autonomous Data Buoy, } \\
\text { physical-biogeochemical model }\end{array}$ \\
\hline Algal bloom & Satellite, Autonomous Data Buoy \\
\hline Zooplankton & Physical-biogeochemical model \\
\hline Fishing & $\begin{array}{l}\text { Responsible authorities } \\
\text { (e.g., fisheries department, fish } \\
\text { landing center, fishing harbor, } \\
\text { fishermen community) }\end{array}$ \\
\hline Habitat & $\begin{array}{l}\text { Satellite, responsible authorities } \\
\text { (e.g., revenue department) }\end{array}$ \\
\hline River discharge & $\begin{array}{l}\text { Water gauge, responsible authorities } \\
\text { (e.g., water resource department) }\end{array}$ \\
\hline
\end{tabular}

fine-tuned coupled physical-biogeochemical model can simulate instantaneous vertical profiles or time evolution of a feature across the water column (Chakraborty et al. 2017). Meteorological parameters can be obtained from atmospheric model forecasts. The proposed conceptual framework based on inputs from ocean biophysical and atmospheric models can be adopted for possible generation of jellyfish forecast/advisories for Indian waters.

\section{Conclusion}

The gelatinous plankton community, including jellyfishes, is an important component of marine food webs. Although jellyfishes often are regarded as "dead-ends" in these food webs, they supply food of several top level consumers-including fishes, sea turtles, and even humans. However, their recurring swarms and beach strandings exert adverse impacts on aquatic ecology and human enterprises. Although jellyfish swarming plays an important role in ecosystem dynamics of coastal waters, environmental variables favoring their aggregations are not well understood. The present review thus highlighted the environmental concerns associated with coastal jellyfish swarming and beach strandings. In Indian coastal waters, jellyfish swarming and strandings have been observed to recur in several pockets, including estuaries and nearshore waters. Physical-chemical-biological parameters that influence growth, reproduction rate, and accumulation of jellyfishes need to be understood for monitoring their swarm dynamics. Furthermore, coastal power plants (i.e., the Madras Atomic Power Station discussed in this article) also are facing issues of temporary shutdowns due to massive numbers of jellyfish in their seawater intake systems' screens for cooling systems. It would be economically and ecologically useful to develop an early warning system to alert power stations about incoming swarms of jellyfish. We thus here recommend a conceptual framework for a possible jellyfish aggregation monitoring advisory using coupled physical-biogeochemical model outputs. On another note, harvest of edible jellyfishes for human consumption will also be helpful for strategic management of jellyfish aggregations in Indian coastal waters.

\section{Abbreviation \\ MAPS: Madras Atomic Power Station}

\section{Acknowledgements}

Authors thank the Director of the Indian National Centre for Ocean Information Services (INCOIS), Hyderabad, for encouragement. Authors gratefully acknowledge Dr. C. Stepien (Associate Editor) for language editing and constructive comments that has significantly improved the manuscript. This study was part of the project entitled "Coastal Monitoring" under the umbrella scheme of "Ocean Services, Modelling, Application, Resources and Technology (O-SMART)," sanctioned by the Ministry of Earth Sciences (MoES) vide Administrative Order (AO) No. MoES/EFC/28/2018-PC-II dated 12-112018 and revised order no. MoES/36/OOIS/CM/2019 dated 07-05-2019. This is INCOIS contribution no. 392

\section{Authors' contributions}

$\mathrm{SKB}, \mathrm{AAL}$, and TMBN conceived the idea and prepared the skeleton of the manuscript. SS collected literature and relevant information. SKB, AAL, and SS prepared the first and final versions of the draft. AS prepared the illustrations. TMBN and NK revised the manuscript. The authors read and approved the final manuscript.

Funding

Not applicable

Availability of data and materials

All data are included in the manuscript.

Ethics approval and consent to participate

No ethics approval or consent was required.

Consent for publication

Not applicable

\section{Competing interests}

On behalf of all authors, the corresponding author states that there are no conflicts of interest.

Received: 28 May 2020 Accepted: 14 October 2020

Published online: 26 October 2020

\section{References}

Amorim K, Mattmuller RM, Alguero-Muniz M, Meunier CL, Alvarez-Fernandez S, Boersma M, Morais P, Teodosio MA (2018) Winter river discharge may affect summer estuarine jellyfish blooms. Mar Ecol Prog Ser 591:253-265

Baliarsingh SK, Lotliker AA, Trainer VL, Wells ML, Parida C, Sahu BK, Srichandan S, Sahoo S, Sahu KC, Kumar TS (2016) Environmental dynamics of red Noctiluca scintillans bloom in tropical coastal waters. Mar Pollut Bull 111(1-2):277-286 
Baliarsingh SK, Srichandan S, Sahu KC, Lotliker AA (2015) Occurrence of a new species of toxic Cnidaria (Pelagia noctiluca Forskal, 1775) from estuarine waters of Rushikulya River, Western Bay of Bengal. Indian J Geo-Mar Sci 44(4):580-582 Baxter EJ, Sturt MM, Ruane NM, Doyle TK, McAllen R, Harman L, Rodger HD (2011) Gill damage to Atlantic salmon (Salmo salar) caused by the common jellyfish (Aurelia aurita) under experimental challenge. PLoS One 6(4):e18529

Behera PR, Raju SS, Jishnudev MA, Ghosh S, Saravanan R (2020) Emerging jellyfish fisheries along central south east coast of India. Ocean Coast Manag 191:105183

Berline L, Zakardjian B, Molcard A, Ourmieres Y, Guihou K (2013) Modeling jellyfish Pelagia noctiluca transport and stranding in the Ligurian Sea. Mar Pollut Bull 70(1-2):90-99

Billett DSM, Bett BJ, Jacobs CL, Rouse IP, Wigham BD (2006) Mass deposition of jellyfish in the deep Arabian Sea. Limnol Oceanogr 51(5):2077-2083

Brodeur RD, Wilson MT, Napp JM, Stabeno PJ, Salo S (1997) Distribution of juvenile Pollock relative to frontal structure near the Pribilof Islands, Bering Sea. In: Proceedings of the international symposium on the role of forage fishes in marine ecosystems. Alaska Sea Grant Publications, Fairbanks, pp 573-589

Brotz L, Cheung WW, Kleisner K, Pakhomov E, Pauly D (2012) Increasing jellyfish populations: trends in large marine ecosystems. In: Purcell J, Mianzan H, Frost JR (eds) Jellyfish BloomsIV, Developments in hydrobiology, vol 220. Springer, Dordrecht, pp 3-20

Cadalmin (2010) Seasonal jellyfish fishery in Jakhau, Gujarat. CMFRI News Letter 127:19

Burnett JW (2001) Medical aspects of jellyfish envenomation: pathogenesis, case reporting and therapy. Hydrobiologia 451:1-9

Chakraborty K, Kumar N, Gupta GVM (2017) Getting the right wind-forcing for an ecosystem model: a case study from the eastern Arabian Sea. J Operational Oceanogr 10(2):176-190

Colombo GA, Benović A, Malej A, Lucic D, Makovec T, Onofri V, Acha M, Madirolas A, Mianzan H (2008) Acoustic survey of a jellyfish-dominated ecosystem (Mljet Island, Croatia). In: Pitt KA, Purcell JE (eds) Jellyfish blooms: causes, consequences, and recent advances. Developments in Hydrobiology, vol 206. Springer, Dordrecht, pp 99-111

De Donno A, Idolo A, Bagordo F, Grassi T, Leomanni A, Serio F, Guido M, Canitano M, Zampardi S, Boero F, Piraino S (2014) Impact of stinging jellyfish proliferations along south Italian coasts: human health hazards, treatment and social costs. Int J Environ Res Public Health 11(3):2488-2503

Deccan Chronicle (2015) Jellyfish bloom off Visakhapatnam coast reported. https:/www.deccanchronicle.com/150227/nation-current-affairs/article/ jellyfish-bloom-visakhapatnam-coast-reported. Accessed 24 Jan 2020

Deccan Herald (2018) Jellyfish scare on Tagore beach in Karwar. https://www. deccanherald.com/state/jellyfish-scare-tagore-beach-697676.html. Accessed 24 Jan 2020

Dong Z, Liu D, Keesing JK (2010) Jellyfish blooms in China: dominant species, causes and consequences. Mar Pollut Bull 60(7):954-963

Doyle TK, De Haas H, Cotton D, Dorschel B, Cummins V, Houghton JD, Davenport J, Hays GC (2008) Widespread occurrence of the jellyfish Pelagia noctiluca in Irish coastal and shelf waters. J Plankton Res 30(8):963-968

DTNEXT (2017) Harmful jellyfish presence on the rise along Rameswaram coast. https:/www.dtnext.in/News/TamilNadu/2017/05/12021447/1033625/Harmfuljellyfish-presence-on-the-rise-along-Rameswaram-vpf. Accessed 24 Jan 2020

Franks PJS (1992) Sink or swim: accumulation of biomass at fronts. Mar Ecol Prog Ser 82:1-12

Galil BS, Kress N, Shiganova TA (2009) First record of Mnemiopsis leidyi A. Agassiz, 1865 (Ctenophora; Lobata; Mnemiidae) off the Mediterranean coast of Israel. Aquat Invasions 4(2):357-360

Ghermandi A, Galil B, Gowdy J, Nunes PA (2015) Jellyfish outbreak impacts on recreation in the Mediterranean Sea: welfare estimates from a socioeconomic pilot survey in Israel. Ecosyst Serv 11:140-147

Graham WM, Martin DL, Martin JC (2003) In situ quantification and analysis of large jellyfish using a novel video profiler. Mar Ecol Prog Ser 254:129-140

Graham WM, Pages F, Hamner WM (2001) A physical context for gelatinous zooplankton aggregations: a review. In: Purcell JE, Graham WM, Dumont HJ (eds) Jellyfish blooms: ecological and societal importance. Springer, Dordrecht, pp 199-212

Han CH, Uye SI (2009) Quantification of the abundance and distribution of the common jellyfish Aurelia aurita s.I with a dual-frequency identification SONar (DIDSON). J Plankton Res 31(8):805-814

Houghton JDR, Doyle TK, Davenport J, Hays GC (2006) Developing a simple, rapid method for identifying and monitoring jellyfish aggregations from the air. Mar Ecol Prog Ser 314:159-170
Johnson DR, Perry HM, Graham WM (2005) Using nowcast model currents to explore transport of non-indigenous jellyfish into the Gulf of Mexico. Mar Ecol Prog Ser 305:139-146

Kaneda A, Kohama T, Kawamura Y, Takeoka H (2007) Periodicity in the accumulation of gelatinous zooplankton during the summer season in the coastal area of lyo-Nada, Japan. Limnol Oceanogr 52(2):707-715

Kim H, Kim D, Jung S, Koo J, Shin JU, Myung H (2015) Development of a UAVtype jellyfish monitoring system using deep learning. In: Proceedings of the 12th International Conference on Ubiquitous Robots and Ambient Intelligence (URAI 2015), Goyang, Korea, 28-30 October 2015

Kumar SB, Mohanty AK, Das NPI, Satpathy KK, Sarkar SK (2017) Impingement of marine organisms in a tropical atomic power plant cooling water system. Mar Pollut Bull 124(1):555-562

Lucas CH, Gelcich S, Uye SI (2014) Living with jellyfish: management and adaptation strategies. In: Pitt K, Lucas C (eds) Jellyfish blooms. Springer, Dordrecht, pp 129-150

Lynam CP, Gibbons MJ, Axelsen BE, Sparks CA, Coetzee J, Heywood BG, Brierley AS (2006) Jellyfish overtake fish in a heavily fished ecosystem. Curr Biol 16(13):R492-R493

Lynam CP, Heath MR, Hay SJ, Brierley AS (2005) Evidence for impacts by jellyfish on North Sea herring recruitment. Mar Ecol Prog Ser 298:157-167

Macrokanis CJ, Hall NL, Mein JK (2004) Irukandji syndrome in northern Western Australia: an emerging health problem. Med J Australia 181(11-12):699-702

Masilamoni JG, Jesudoss KS, Nandakumar K, Satpathy KK, Nair KVK, Azariah J (2000) Jellyfish ingress: a threat to the smooth operation of coastal power plants. Curr Sci 79(5):567-569

MPEDA (2020) The marine product development authority (MPEDA). State-wise aquaculture productivity. Area utilized and production of Tiger and $L$. vannamei shrimp during 2017-18. http://mpeda.gov.in . . Accessed 16 Sept 2020

Nickell T, Davidson K, Fox C, Miller P, Hays G (2010) Developing the capacity to monitor the spatial and temporal distribution of jellyfish in western Scottish waters. The Crown Estate, London

Pitt KA, Koop K, Rissik D (2005) Contrasting contributions to inorganic nutrient recycling by the co-occurring jellyfishes, Catostylus mosaicus and Phyllorhiza punctata (Scyphozoa, Rhizostomeae). J Exp Mar Biol Ecol 315(1):71-86

Purcell JE, Baxter EJ, Fuentes VL (2013) Jellyfish as products and problems of aquaculture. In: Allan G, Burnell G (ed) Advances in Aquaculture Hatchery Technology, Woodhead Publishing

Purcell JE (2005) Climate effects on formation of jellyfish and ctenophore blooms: a review. J Mar Biol Assoc UK 85:461-476

Purcell JE, Baxter EJ, Fuentes VL (2013) Jellyfish as products and problems of aquaculture. In: Allan G, Burnell G (eds) Advances in aquaculture hatchery technology. Woodhead Publishing, pp 404-430

Purcell JE, Uye SI, Lo WT (2007) Anthropogenic causes of jellyfish blooms and their direct consequences for humans: a review. Mar Ecol Prog Ser 350:153-174

Richardson AJ, Bakun A, Hays GC, Gibbons MJ (2009) The jellyfish joyride: causes, consequences and management responses to a more gelatinous future. Trends Ecol Evol 24(6):312-322

Sahu BK, Baliarsingh SK, Samanta A, Srichandan S, Singh S (2020) Mass beach stranding of blue button jellies (Porpita porpita, Linnaeus, 1758) along Odisha coast during summer season. Indian J Geo-Mar Sci 49(6):1093-1096

Sahu BK, Panigrahy RC (2013) Jellyfish bloom along the South Odisha coast, bay of Bengal. Curr Sci 104(4):410-411

Shiganova TA (1998) Invasion of the Black Sea by the ctenophore Mnemiopsis leidyi and recent changes in pelagic community structure. Fish Oceanogr 7(3-4):305-310

Sullivan BK, Van Keuren D, Clancy M (2001) Timing and size of blooms of the ctenophore Mnemiopsis leidyi in relation to temperature in Narragansett Bay, RI. Hydrobiologia 451:113-120

Sweetman AK, Chapman A (2011) First observations of jelly-falls at the seafloor in a deep-sea fjord. Deep Sea Res Part I: Oceanogr Res Papers 58(12):1206-1211

The Economic Times (2014) Jellyfish blooms and Ganapati immersions. https://economictimes.indiatimes.com/blogs/onmyplate/jellyfish-bloomsand-ganapati-immersions/. Accessed 24 Jan 2020

The Hindu (2013) Jellyfish proliferating along Kerala coast. https://www.thehindu. com/news/national/kerala/jellyfish-proliferating-along-kerala-coast/article535 7801.ece. Accessed 24 Jan 2020

The Hindu (2015) Four giant jellyfish washed ashore. https://www.thehindu.com/ news/national/andhra-pradesh/four-giant-jellyfish-washed-ashore/article7646 789.ece. Accessed 24 Jan 2020 
The Hindu (2016) Dead jellyfish wash ashore at Puri coast; govt. seeks Centre's help. https://www.thehindu.com/news/national/other-states/dead-jellyfishwash-ashore-at-puri-coast-govt-seeks-centres-help/article8553085.ece. Accessed 24 Jan 2020

The Hindu (2019) Coin-sized creatures beached on Chennai shores. https://www. thehindu.com/sci-tech/energy-and-environment/coin-sized-creaturesbeached-on-chennai-shore/article26508761.ece. Accessed 24 Jan 2020

The Indian Express (2018) Over 100 stung by jellyfish in last two days. https:// indianexpress.com/article/cities/mumbai/over-100-stung-by-jellyfish-in-lasttwo-days-5294821/. Accessed 24 Jan 2020

The Sambad (2016) Carcasses of blue button jellyfish DOT Odisha coast. https:// sambadenglish.com/carcasses-of-blue-button-jellyfish-dot-odisha-coast/ \#: :text=Puri\%2C\%20May\%2015\%3A,coast\%20in\%200disha's\%20Puri\%2 Odistrict . . Accessed 17 Sept 2020

The Sambad (2018) Poisonous jellyfishes found dead at Puri beach in Odisha. https://sambadenglish.com/poisonous-jellyfishes-found-dead-at-puri-beachin-odisha/. Accessed 24 Jan 2020

The Statesman (2018) Jellyfish can be fatal. https:/www.thestatesman.com/ supplements/8thday/jellyfish-can-be-fatal-1502704640.html. Accessed 24 Jan 2020

Times of India (2015) Tourists feel the sting as jellyfish invade coastline in Goa. https:/timesofindia.indiatimes.com/city/goa/Tourists-feel-the-sting-as-jellyfishinvade-coastline-in-Goa/articleshow/49498033.cms. Accessed 24 Jan 2020

Times of India (2019) Purple jellyfish spotted on Colva-Benaulim beach stretch. https:/timesofindia.indiatimes.com/city/goa/purple-jellyfish-spotted-on-colvabenaulim-beach-stretch/articleshow/67480201.cms. Accessed 24 Jan 2020

Xu Y, Ishizaka J, Yamaguchi H, Siswanto E, Wang S (2013) Relationships of interannual variability in SST and phytoplankton blooms with giant jellyfish (Nemopilema nomurai) outbreaks in the Yellow Sea and East China Sea. J Oceanogr 69:511-526

Zavodnik D (1987) Spatial aggregations of the swarming jellyfish Pelagia noctiluca (Scyphozoa). Mar Biol 94:265-269

\section{Publisher's Note}

Springer Nature remains neutral with regard to jurisdictional claims in published maps and institutional affiliations.

\section{Submit your manuscript to a SpringerOpen ${ }^{\circ}$ journal and benefit from:}

- Convenient online submission

- Rigorous peer review

- Open access: articles freely available online

- High visibility within the field

- Retaining the copyright to your article

Submit your next manuscript at $\boldsymbol{\nabla}$ springeropen.com 